Article

\title{
Beyond Depression and Suicide: The Mental Health of Transgender College Students
}

\author{
Sara B. Oswalt ${ }^{1, *}$ and Alyssa M. Lederer ${ }^{2}$ \\ 1 Department of Kinesiology, Health and Nutrition, University of Texas at San Antonio, San Antonio, \\ TX 78249, USA \\ 2 Department of Global Community Health and Behavioral Sciences, Tulane University School of Public \\ Health and Tropical Medicine, New Orleans, LA 70112, USA; alederer@tulane.edu \\ * Correspondence: sara.oswalt@utsa.edu; Tel.: +1-210-458-6227
}

Academic Editor: Elbert P. Almazan

Received: 30 December 2016; Accepted: 15 February 2017; Published: 21 February 2017

\begin{abstract}
Research studies examining the mental health of transgender individuals often focus on depression, anxiety, and suicidal ideation through the use of clinic samples. However, little is known about the emerging adult (18-26 years old) transgender population and their mental health. The current study seeks to fill that gap by using a national dataset of college students $(\mathrm{N}=547,727)$ to examine how transgender college students $(n=1143)$ differ from their cisgender peers regarding 12 different mental health conditions. Chi-square and regression analyses were conducted. Results demonstrate that transgender students have approximately twice the risk for most mental health conditions compared to cisgender female students. A notable exception is schizophrenia, in which transgender individuals have about seven times the risk compared to cisgender females. While these were significant findings, regression analyses indicate that being non-heterosexual is a greater predictor for mental health concerns. Implications for mental health practitioners at colleges and universities are discussed.
\end{abstract}

Keywords: gender identity; transgender; mental health; college student; college health; depression; anxiety; schizophrenia; gender nonconforming

\section{Introduction}

In recent years, there has been a substantial increase in research examining health disparities among sexual and gender minorities. While this research has helped health professionals better understand a number of critical issues among this priority population, a major limitation has been that most studies only focus on sexual orientation or are based on group-level analyses without examining specific subpopulations within the queer community-especially individuals who identify as transgender [1]. For the few studies examining the transgender population, most lack a sample large enough to adequately determine the prevalence of health issues among these individuals [2]. In order to fill these gaps, the purpose of this study is to examine the mental health concerns of transgender-identified college students using a national dataset from a six-year period.

The U.S. National Institutes of Health has designated sexual and gender minorities as a health disparity population [3], and the Institute of Medicine has recommended expanding research on transgender individuals [2]. The term transgender typically refers to individuals whose gender identity and/or gender expression is not congruent with the sex they were assigned at birth. For some individuals, this may mean that they want to transition from one gender to another, while for others it may indicate a dissatisfaction with the gender binary as applicable to their identity. These individuals may identify as transgender, genderqueer, gender fluid, gender non-conforming, or other related terms [4]. 
Examination of mental health issues beyond gender dysphoria is warranted to better understand the experiences of this population. Carmel and Erickson-Schroth's review [5] of the literature has indicated that transgender and gender non-conforming (TGNC) individuals are at increased risk for depression, substance use disorders, self-injury, and suicidal ideation/attempts. The rates and potential increased risk for other mental health conditions such as anxiety disorders, post-traumatic stress disorder, bipolar disorder, psychotic disorders, eating disorders, body dysmorphic disorders, autism spectrum disorders, and personality disorders are less conclusive. Other research that compares experiences of transgender individuals and cisgender individuals (those whose gender identity/expression is congruent with the sex assigned at birth) indicate higher rates of reported discrimination, depressive symptoms, and attempted suicides among those with a transgender identity compared to non-heterosexuals with a cisgender identity [6]. Discrimination and lack of family or other social support have all been shown to negatively affect mental health issues [6-9], while social and peer support have been shown to moderate depression, anxiety, and somatization in transgender individuals [10]. While not peer-reviewed, the largest recent examination of transgender experiences found that almost $40 \%$ of respondents experienced serious psychological distress in the month prior to completing the survey and $40 \%$ had attempted suicide in their lifetime; a rate nearly nine times that of the general U.S. population [11].

Of the existing research that examines the mental health of transgender individuals, few focus on adolescents and emerging adults (defined as 18-26 years old [12]). A 2016 review of the literature [13] specifically focusing on transgender youth found higher rates of depression, suicidality, self-harm, and eating disorders when compared with their non-transgender peers. For example, Reisner and colleagues' study [14] of transgender-identified youth between 12 and 29 years old found that transgender-identified youth had a two-to-three times increased risk of depression, anxiety disorder, suicidal ideation, suicide attempt, self-harm without lethal intent, and both inpatient and outpatient mental health treatment compared to matched (by age, ethnicity, date of visit) cisgender controls attending a community health clinic. While this study provided useful comparison data and included ethnicity (another demographic linked to mental health status), it did not address the intersection of sexual orientation with gender identity. Similar to other studies on transgender individuals, those focused on transgender youth are typically conducted through clinical settings specializing in gender, and involve only a small number of participants [13].

With 12.2 million people under the age of 25 enrolled at degree-granting postsecondary institutions in the United States, representing $40 \%$ of the overall United States population of 18 to 24 year olds [15], institutions of higher education can be a key setting for reaching TGNC individuals and understanding their experiences. Similarly, adolescence and young adulthood are often the first time mental health issues are identified and diagnosed [16]. For these reasons, focusing on transgender-identified college students can help health professionals and the general public to better understand the experiences of this population and issues they may face in the future. This study used the American College Health Association-National College Health Assessment (ACHA-NCHA) II to examine mental health conditions in college students who identify as transgender. The specific research questions were:

- Do transgender college students report increased rates of diagnosis and treatment of mental health conditions compared to their cisgender peers?

- How is gender identity linked to mental health conditions when considering other demographic factors?

\section{Methods}

The ACHA-NCHA II survey is conducted every fall and spring at North American postsecondary institutions. These institutions self-select to administer the survey in partnership with the American College Health Association. Survey responses are only included in the national dataset from institutions that randomly selected students or classrooms or that surveyed all students at their school. The current study used cross-sectional survey data from schools participating in Spring 2009 (117 schools), Spring 
2010 (129 schools), Spring 2011 (129 schools), Spring 2012 (141 schools), Spring 2013 (153 schools), and Spring 2014 (140 schools) [17].

Across the six years, the sample included data from 429 unique institutions from all regions of the United States and nine institutions outside the U.S. Students completed either paper or web surveys, depending on the format offered at their institution. Response rates were high for paper surveys (mean response proportions ranged from $81 \%$ (in 2011) to $93 \%$ (in 2013)) but lower for web surveys (mean response proportions ranged from 18\% (in 2013 and 2014) to 21\% (in 2010 and 2011)). Respondents anonymously completed surveys during a specific time period selected by each school's administration. Institutions obtained approval of study procedures from their own Institutional Review Board (IRB) and the lead author's IRB considered the current study exempt from review because it was secondary data analysis with a de-identified dataset.

\subsection{Measures}

While the ACHA-NCHA II consists of 66 items, one multi-part item was the focus for this study. Students were asked "Within the last 12 months, have you been diagnosed or treated by a professional for any of the following..." with a list that included anorexia, anxiety, attention deficit and hyperactivity disorder (ADHD), bipolar disorder, bulimia, depression, insomnia, obsessive compulsive disorder (OCD), panic attacks, phobia, schizophrenia, and substance abuse/addiction. Response options for each condition were no; yes, diagnosed but not treated; yes, treated with medication; yes, treated with psychotherapy; yes, treated with medication and psychotherapy; or yes, other treatment. Since the focus of the study was to examine rates of mental health among transgender students and the effect of gender, responses were collapsed to a dichotomous response of "not diagnosed or treated within the last 12 months" or "diagnosed or treated in the last 12 months."

Three demographic characteristics were considered to be a critical part of the analyses. The primary variable of interest—gender identity—was measured by asking: "What is your gender?" The three response options were: female, male, and transgender. Individuals who did not identify a gender ( $n=12,859)$ were eliminated from the analyses. Race/ethnicity was another demographic variable included in the analyses. On the ACHA-NCHA II, individuals are asked to indicate their race/ethnicity and can mark more than one category. To accommodate analyses, individuals who marked more than one response were recoded as biracial/multi-racial and removed from the individual categories they had initially marked. The last demographic variable of interest was sexual orientation, with response categories of heterosexual, gay/lesbian, bisexual, and unsure.

\subsection{Participants}

For the six data collection periods, a total of 581,603 students completed all or part of the survey. For this study, only students who indicated their gender and responded to all of the mental health conditions were included. Additionally, individuals who were identified as outliers were eliminated from the analyses. Outlier criteria was based on improbable responses; i.e., reporting six or seven of the seven race categories $(n=392)$ or reporting 11 or 12 of the 12 possible mental health issues $(n=653)$. After the exclusion/inclusion criteria were applied, the total analytic sample was 547,727.

Most participants were cisgender female $(65.1 \%, \mathrm{n}=356,511)$, with less than $1 \%$ identifying as transgender $(0.2 \%, \mathrm{n}=1143)$. Most students completing the survey were White $(68.1 \%, \mathrm{n}=369,574)$ with $10.5 \%$ identifying as Asian/Pacific Islander $(n=57,035)$. Biracial/Multiracial was the next most common race/ethnicity $(8.1 \%, \mathrm{n}=44,042)$, followed by Hispanic $(6.6 \%, \mathrm{n}=35,972)$, Black $(4.7 \%$, $\mathrm{n}=25,401)$, American Indian/Alaskan Native/Native Hawaiian $(0.4 \%, \mathrm{n}=2406)$, or other $(1.6 \%$, $\mathrm{n}=8633)$. There were almost equal distributions between years in school, with $22.8 \%(\mathrm{n}=123,355)$ of participants being first-year students, $20.1 \%(\mathrm{n}=108,916)$ second-year, $19.8 \%(\mathrm{n}=107,475)$ third-year, $16.2 \%(\mathrm{n}=87,714)$ fourth-year, $5.2 \%(\mathrm{n}=28,347)$ fifth-year or more undergraduate, and $14.7 \%$ $(\mathrm{n}=79,638)$ as a graduate student. About $1 \%$ were not seeking a degree $(0.4 \%, \mathrm{n}=2232)$ or identified another status $(0.7 \%, \mathrm{n}=3903)$. Most students were full-time $(91.5 \%, \mathrm{n}=496,598)$, and about $10 \%$ were 
international students $(9.3 \%, \mathrm{n}=50,582)$. Most students were heterosexual $(91.7 \%, \mathrm{n}=497,817)$, with $2.8 \%(n=15,039)$ identifying as gay/lesbian, $3.6 \%(n=19,756)$ identifying as bisexual, $1.9 \%(n=10,156)$ identifying as unsure. Most students had health insurance, with almost two-thirds $(63.9 \%, n=342,586)$ being covered through their parents' plan. Slightly over $15 \%(15.5 \%, n=82,844)$ were covered by the university or college plan, and an additional $12.8 \%(n=68,567)$ were covered by another plan.

Regarding ethnicity, transgender students were predominately White, though a lower percentage compared to the overall group $(63.0 \%, \mathrm{n}=709)$. Almost one in five transgender students were biracial/multiracial $(17.8 \%, \mathrm{n}=200)$ with the next largest group identifying as other $(6 \%, \mathrm{n}=67)$. Less than $15 \%$ identified as either Asian Pacific Islander $(4.8 \%, n=54)$, Black $(3.7 \% n=42)$, Hispanic $(4.3 \%, \mathrm{n}=48)$, or American Indian, Alaskan Native, Native Hawaiian $(0.5 \%, \mathrm{n}=6)$. Among those who identified as transgender, there was an almost equal distribution among the various sexual orientations: $23.7 \%(n=264)$ identified as heterosexual, $21.9 \%(n=244)$ identified as gay /lesbian, $31.7 \%(n=354)$ identified as bisexual, and $22.8 \%(n=254)$ identified as unsure.

\subsection{Analyses}

Frequencies were calculated for the demographic and dependent variables of interest. Chi-square was used to examine frequency differences in mental health conditions among genders (cisgender male, cisgender female, transgender). Cramer's V was used to measure effect size, as it is considered robust regardless of table size. Binary logistic regressions were conducted, with gender, ethnicity, and sexual orientation as the independent variables. Ethnicity and sexual orientation were included, as previous research indicates that ethnicity [18-22] and sexual orientation [23,24] affect the mental health of college students. All analyses were conducted using IBM SPSS Version 22. Because of the large sample size, a Bonferroni correction was applied which resulted in setting the $p$ value at $<0.004$. As a result, $99.996 \%$ confidence intervals were used in the analyses.

\section{Results}

Most students reported no mental health diagnoses or treatment within the last 12 months for the 12 conditions examined. The mental health concerns with the three highest frequencies were anxiety (11.6\% reporting the condition overall, with $33.4 \%$ of transgender-identified students reporting the condition); depression (10.4\% overall, $34.3 \%$ of transgender-identified students); and panic attacks (5.3\% overall, with $16.5 \%$ of transgender-identified students). Table 1 includes percentages and frequencies for all 12 conditions by gender identity. While the chi-square values for all 12 conditions were significant at the 0.004 level, the effect sizes were small (ranging from 0.02 to 0.12 ). Subsequently, logistic regression was employed to ascertain a better understanding of how transgender identity and the other demographic variables affected the risk for these mental health conditions.

The logistic regression indicated that transgender students were significantly more likely to be diagnosed/treated for all 12 conditions in the previous 12 months (as shown in Table 2). However, for almost all conditions (except for schizophrenia), a non-heterosexual sexual orientation was a greater risk than identifying as transgender. In most cases, the odds ratio indicated that transgender-identified students were approximately twice as likely to have the mental health condition compared to self-identified cisgender females. The notable exceptions were panic attacks, which had an odds ratio of 1.52 (99.996\% CI 1.08-2.13), bipolar disorder with an odds ratio of 2.34 (99.996\% CI 1.43-3.81), and schizophrenia with an odds ratio of 7.85 (99.996\% CI 2.84-21.42). Similarly, transgender students had higher odds ratios for all mental health conditions compared to cisgender males-even for conditions where cisgender males had greater risk than cisgender females (i.e., ADHD, schizophrenia, and substance abuse/addiction). See Table 2 for logistic regression analyses with odds ratios (OR) and confidence intervals. 
Table 1. Percentage of students diagnosed/treated in last 12 months.

\begin{tabular}{ccccc}
\hline & $\begin{array}{c}\text { Cisgender } \\
\text { Female } \\
\mathbf{\%}(\mathbf{n})\end{array}$ & $\begin{array}{c}\text { Cisgender } \\
\text { Male } \\
\mathbf{\%}(\mathbf{n})\end{array}$ & $\begin{array}{c}\text { Transgender } \\
\mathbf{\%}(\mathbf{n})\end{array}$ & $\begin{array}{c}\text { Total } \\
\mathbf{\%}(\mathbf{n})\end{array}$ \\
\hline Anorexia & $1.2(4147)$ & $0.2(438)$ & $3.6(41)$ & $0.8(4626)$ \\
Anxiety & $14.1(50,365)$ & $6.6(12,534)$ & $33.4(382)$ & $11.6(63,281)$ \\
ADHD & $4.1(14,471)$ & $4.6(8769)$ & $11.9(136)$ & $4.3(23,376)$ \\
Bipolar disorder & $1.3(4754)$ & $1.0(1841)$ & $7.4(85)$ & $1.2(6680)$ \\
Bulimia & $1.1(3806)$ & $0.2(406)$ & $3.3(38)$ & $0.8(4250)$ \\
Depression & $12.3(43,886)$ & $6.5(12,443)$ & $34.3(392)$ & $10.4(56,721)$ \\
Insomnia & $4.1(14,734)$ & $2.7(5116)$ & $0.7(145)$ & $3.7(1995)$ \\
OCD & $2.2(7978)$ & $1.3(2536)$ & $8.0(91)$ & $1.9(10,605)$ \\
Panic attacks & $6.8(24,099)$ & $2.5(4705)$ & $16.5(193)$ & $5.3(28,997)$ \\
Phobia & $1.0(3575)$ & $0.5(888)$ & $4.0(46)$ & $0.8(4509)$ \\
Schizophrenia & $0.1(286)$ & $0.2(311)$ & $1.9(22)$ & $0.1(619)$ \\
Substance abuse/addiction & $0.8(2782)$ & $1.2(2208)$ & $3.6(41)$ & $0.9(5031)$ \\
\hline
\end{tabular}

Notes: All chi-square values were significant $p<0.001$; ADHD: Attention deficit and hyperactivity disorder; OCD: obsessive compulsive disorder. 
Table 2. Regression analyses for mental health diagnoses.

\begin{tabular}{|c|c|c|c|c|c|c|}
\hline & Anorexia & Anxiety & ADHD & Bipolar Disorder & Bulimia & Depression \\
\hline & OR $(99.996 \%$ CI) & OR $(99.996 \%$ CI $)$ & OR $(99.996 \%$ CI) & OR $(99.996 \%$ CI) & OR $(99.996 \%$ CI $)$ & OR $(99.996 \%$ CI $)$ \\
\hline Cisgender Female & Reference & Reference & Reference & Reference & Reference & Reference \\
\hline Cisgender Male & $0.20 *(0.16-0.24)$ & $0.42 *(0.41-0.44)$ & $1.16 *(1.10-1.23)$ & $0.74 *(0.66-0.83)$ & $0.19 *(0.16-0.24)$ & $0.50 *(0.47-0.52)$ \\
\hline Transgender & $1.88 *(0.96-3.68)$ & $1.71 *(1.31-2.24)$ & $2.02 *(1.36-2.99)$ & $2.34 *(1.43-3.81)$ & $1.84 *(0.91-3.72)$ & $1.91 *(1.46-2.50)$ \\
\hline Heterosexual & Reference & Reference & Reference & Reference & Reference & Reference \\
\hline Gay/Lesbian & $2.03 *(1.46-2.82)$ & $2.44 *(2.23-2.68)$ & $1.60 *(1.39-1.84)$ & $3.08 *(2.49-3.81)$ & $2.10 *(1.50-2.95)$ & $2.66 *(2.43-2.92)$ \\
\hline Bisexual & $2.28 *(1.83-2.84)$ & $2.48 *(2.31-2.67)$ & $2.04 *(1.82-2.28)$ & $4.48 *(3.85-5.22)$ & $2.16 *(1.71-2.73)$ & $2.97 *(2.76-3.19)$ \\
\hline Unsure & $1.93 *(1.37-2.72)$ & $1.86 *(1.67-2.08)$ & $1.66 *(1.40-1.98)$ & $2.48 *(1.90-3.25)$ & $2.05 *(1.45-2.89)$ & $2.12 *(1.90-2.37$ \\
\hline White & Reference & Reference & Reference & Reference & Reference & Reference \\
\hline Black & $0.24 *(0.14-0.40)$ & $0.41 *(0.37-0.46)$ & $0.36 *(0.30-0.44)$ & $0.77 *(0.59-1.00)$ & $0.43 *(0.28-0.66)$ & $0.51 *(0.46-0.57)$ \\
\hline Hispanic & $0.50 *(0.36-0.69)$ & $0.56 *(0.51-0.61)$ & $0.45 *(0.39-0.52)$ & $0.74 *(0.58-0.93)$ & $0.74 *(0.55-0.99)$ & $0.63 *(0.58-0.69)$ \\
\hline Asian and PI & $0.59 *(0.46-0.76)$ & $0.33 *(0.31-0.36)$ & $0.29 *(0.25-0.33)$ & $0.48 *(0.38-0.61)$ & $0.71 *(0.56-0.91)$ & $0.42 *(0.38-0.45)$ \\
\hline $\mathrm{AM}, \mathrm{AN}, \mathrm{NH}$ & $0.59(0.20-1.78)$ & $0.79 *(0.60-1.03)$ & $0.88(0.59-1.33)$ & $1.51(0.83-2.77)$ & $0.78(0.28-2.20)$ & $0.89(0.67-1.17)$ \\
\hline Biracial/Multiracial & $0.98(0.80-1.21)$ & $0.89 *(0.84-0.95)$ & $0.99(0.90-1.09)$ & $1.18 *(1.00-1.39)$ & $1.14(0.93-1.41)$ & $0.96(0.90-1.02)$ \\
\hline \multirow[t]{3}{*}{ Other Race/Ethnicity } & $0.71(0.40-1.23)$ & $0.71 *(0.61-0.83)$ & $0.75 *(0.60-0.95)$ & $1.12(0.77-1.62)$ & $0.80(0.46-1.41)$ & $0.77 *(0.66-0.90)$ \\
\hline & Insomnia & OCD & Panic Attacks & Phobia & Schizophrenia & Substance abuse/addiction \\
\hline & OR $(99.996 \%$ CI) & OR $(99.996 \%$ CI) & OR $(99.996 \%$ CI) & OR $(99.996 \%$ CI) & OR $(99.996 \%$ CI $)$ & OR $(99.996 \%$ CI) \\
\hline Cisgender Female & Reference & Reference & Reference & Reference & Reference & Reference \\
\hline Cisgender Male & $0.64 *(0.60-.69)$ & $0.59 *(0.54-0.65)$ & $0.35 *(0.33-0.37)$ & $0.46 *(0.39-0.54)$ & $2.15 *(1.52-3.64)$ & $1.53 *(1.35-1.72)$ \\
\hline Transgender & $1.83 *(1.25-2.68)$ & $2.04 *(1.28-3.26)$ & $1.52 *(1.08-2.13)$ & $1.92 *(1.01-3.65)$ & $7.85 *(2.84-21.42)$ & $2.18 *(1.10-4.32)$ \\
\hline Heterosexual & Reference & Reference & Reference & Reference & Reference & Reference \\
\hline Gay/Lesbian & $2.30 *(2.00-2.65)$ & $2.28 *(1.88-2.75)$ & $2.35 *(2.07-2.67)$ & $2.54 *(1.91-3.38)$ & $2.18 *(1.07-4.46)$ & $2.42 *(1.90-3.09)$ \\
\hline Bisexual & $2.73 *(2.45-3.04)$ & $2.46 *(2.13-2.86)$ & $2.66 *(2.42-2.91)$ & $3.02 *(2.46-3.70)$ & $4.62 *(2.75-7.75)$ & $3.41 *(2.80-4.16)$ \\
\hline Unsure & $1.70 *(1.42-2.04)$ & $1.87 *(1.47-2.37)$ & $1.70 *(1.45-1.99)$ & $2.61 *(19.2-3.56)$ & $5.17 *(2.81-9.51)$ & $2.08 *(1.49-2.92)$ \\
\hline White & Reference & Reference & Reference & Reference & Reference & Reference \\
\hline Black & $0.70 *(0.60-0.82)$ & $0.36 *(0.27-0.48)$ & $0.46 *(0.39-0.53)$ & $0.56 *(0.38-0.81)$ & $2.38 *(1.24-4.54)$ & $0.49 *(0.33-0.71)$ \\
\hline Hispanic & $0.81 *(0.71-0.92)$ & $0.49 *(0.40-0.61)$ & $0.64 *(0.57-0.72)$ & $0.80 *(0.61-1.05)$ & $1.85 *(1.00-3.43)$ & $0.67 *(0.51-0.88)$ \\
\hline Asian \& PI & $0.61 *(0.54-0.69)$ & $0.32 *(0.26-0.39)$ & $0.27 *(0.23-0.31)$ & $0.51 *(0.38-0.67)$ & $1.74 *(1.04-2.92)$ & $0.35 *(0.26-0.47)$ \\
\hline $\mathrm{AM}, \mathrm{AN}, \mathrm{NH}$ & $1.47 *(1.01-2.12)$ & $0.98(0.55-1.73)$ & $0.87(0.60-1.26)$ & $1.25(0.56-2.79)$ & $1.98(0.25-15.75)$ & $2.40 *(1.38-4.17)$ \\
\hline Biracial/Multiracial & $1.18 *(1.07-1.30)$ & $1.06(0.92-1.21)$ & $0.95(0.87-1.04)$ & $1.22 *(1.00-1.49)$ & $2.09 *(1.25-3.49)$ & $1.05(0.86-1.28)$ \\
\hline Other Race/Ethnicity & $1.06(0.84-1.33)$ & $0.80(0.57-1.13)$ & $0.81 *(0.66-1.00)$ & $1.20(0.77-1.86)$ & $4.17 *(1.98-8.80)$ & $1.01(0.65-1.56)$ \\
\hline
\end{tabular}

Notes: $p<0.004 \cdot \mathrm{OR}=$ odds ratio $\mathrm{CI}=$ confidence interval; PI = Pacific Islander; AM, AN, NH = American Indian, Alaskan Native \& Native Hawaiian. 


\section{Discussion}

This study provides the first examination of gender identity as a predictor for a variety of mental health issues in college students using a national survey. The current study's results support other studies that indicate higher rates for mental health conditions-like anxiety and depression-among transgender-identified individuals [5-7,13,14]. Most importantly, the odds ratios indicate that transgender-identified students had significantly greater risk for all mental health conditions than their cisgender peers. While there are also significant differences between cisgender males and cisgender females, because these differences are well-established in the literature [25] and are not the focus of the current study, they are not discussed in detail. Another strength of this study is the inclusion of many mental health conditions beyond depression and suicide, which tend to be the focus of most other studies [5]. This expanded focus increases mental health providers' understanding of the various conditions that TGNC students may be experiencing instead of reinforcing perceptions that depression, anxiety, and suicide are the only concerns that TGNC students face.

At the same time, risk for most mental health conditions for non-heterosexuals did surpass those indicated for transgender individuals, with bisexual-identified individuals having the highest risk. The focus of the current study was to expand awareness around transgender college students' mental health, though it would be beneficial for future studies to better explore this consequential finding.

This article focused on the individual's experience with mental health; however, other levels of the social-ecological model also need to be considered regarding their impact on mental health. For all TGNC individuals, social and familial support are protective factors [5,7]—especially for youth [8,9]. Olson's work [8] indicates that transgender children who have socially transitioned and are supported have developmentally normal levels of depression with only slightly higher levels of anxiety than cisgender children. It is unclear what role social and family support may have on the mental health conditions examined in this study and for college students; these are certainly areas for future research. Additionally, the campus and legal environment play a critical role in discrimination or acceptance of TGNC individuals by others, which can also affect TGNC individuals' mental health. Studies on campus climate for the queer community have been conducted for decades, but few specifically focus on the perceptions and needs of TGNC students. Understanding how the specific climate of a campus affects mental health could be invaluable for campuses working to become more inclusive. Examination of state non-discrimination laws showed that individuals residing in states without nondiscrimination laws reported higher levels of perceived community stigma, which was positively related to lifetime suicide attempt and marginally associated with current symptoms of anxiety [26]. In addition to perceived campus climate, future studies could examine correlations between campus non-discrimination policies that include gender identity and expression with the mental health of transgender students. Understanding these environmental factors alongside demographic variables would critically enhance our understanding of transgender students' mental health and their needs in the university setting.

Because of the sampling method and the self-selection of institutions that implement the ACHA-NCHA II, the survey results are limited in their generalizability. In general, the overall survey provides similar results to nationally representative surveys [27]; however, it is unknown how representative the survey is of the transgender college student population. Estimates of the transgender population are about $1 \%$; however, only $0.2 \%$ of the respondents identified as transgender in the ACHA-NCHA II. Possible reasons for this difference could be that the survey asks for current gender identity. Individuals who have transitioned from one gender to another may identify as male or female, and not mark transgender. Some students may not yet identify as transgender or may not want to commit to a transgender identity. Additionally, students who identify as genderqueer, non-binary or other gender non-conforming identities may have not responded to this item and therefore were not included in the analyses. In 2015, ACHA revised the ACHA-NCHA II to expand questions and responses regarding gender and sex. Instead of the single item asking "what is your gender," three items now ask "What sex were you assigned at birth, such as on an original birth certificate?" (response 
options: female/male); "Do you identify as transgender?" (response options: yes/no); and “Which term do you use to describe your gender identity?" (response options: woman, man, trans woman, trans man, genderqueer, another identity (with a write-in option)). Re-examination of the current study's research questions considering these new response options should be undertaken once data are made available by the organization to better understand the connection between gender identity and mental health.

Additionally, experiences of transgender youth in middle and high school may have included discrimination and other challenges that prevented continuation to college, so the college student sample may not be representative of the actual rate of transgender individuals in the overall emerging adult population. It is also unknown how transgender college students' mental health may differ from other individuals who are not attending college; transgender college students may potentially experience fewer mental health concerns because they may receive more support through campus resources (e.g., student groups and counseling services) than those of the same age not attending college. Another limitation is that demographic and other student characteristics beyond gender, sexual orientation and ethnicity were not examined. While these variables have been consistently identified in the literature as predictors of college students' mental health [17-23], it is possible that other factors (e.g., living on campus vs. not living on campus, having health insurance) may also be related to one's current mental health.

With over one-third of transgender individuals reporting a negative experience with a healthcare provider and one-quarter not seeking health services because of a fear of mistreatment [11], college health services and counseling centers need to be sensitive to the needs of transgender students from initial intake through the clinical experience. Donatone and Rachlin [28] provide a template for intake and initial assessment with TGNC students. Their protocol helps familiarize mental health clinicians with gender-affirming language and provides a list of questions to ask students. Moreover, the American College Health Association [29] created guidelines to assist college health centers in creating trans-inclusive college health programs. While some of these guidelines focus specifically on mental health (identifying knowledgeable providers, explaining services related to transitioning under student health insurance plans, offering support groups for TGNC students); other strategies are designed to improve transgender students' access to health services overall-increasing healthcare access, modifying administrative processes to accommodate TGNC students' needs related to names and paperwork, training of personnel, and adapting health promotion strategies that focus on TGNC students' needs. These strategies can benefit all TGNC students, and minimize potential negative effects caused from accessing services. Similarly, college counseling and mental health centers can examine their campus climate and partner with other entities both on- and off-campus to create a supportive environment. Many campuses have queer student associations or LGBTQ centers which can be ideal partners to address the campus climate as well as provide direct outreach to TGNC students for all mental health conditions-not just depression and suicide. Given the high rates of mental health conditions among transgender college students, ensuring that their mental health needs are known and addressed is critical for this population's current and future well-being.

Acknowledgments: The opinions, findings, and conclusions presented/reported in this article are those of the author(s), and are in no way meant to represent the corporate opinions, views, or policies of the American College Health Association (ACHA). ACHA does not warrant nor assume any liability or responsibility for the accuracy, completeness, or usefulness of any information presented in this article/presentation.

Author Contributions: Sara B. Oswalt and Alyssa M. Lederer conceived the project and methodology. Sara B. Oswalt wrote the first draft of the paper.

Conflicts of Interest: The authors declare no conflict of interest. 


\section{References}

1. Mathy, Robin M., Barbara A. Lehmann, and Deborah L. Kerr. "Bisexual and transgender identities in a nonclinical sample of North Americans: Suicidal intent, behavioral difficulties, and mental health treatment." Journal of Bisexuality 3 (2004): 93-109. [CrossRef]

2. Institute of Medicine. The Health of Lesbian, Gay, Bisexual, and Transgender People: Building a Foundation for Better Understanding. Washington: National Academies Press, 2011.

3. Pérez-Stable, Eliseo J. "Sexual and gender minorities formally designated as a health disparity population for research purposes." 6 October 2016. Available online: http://www.nimhd.nih.gov/about/directorscorner/message.html (accessed on 27 December 2016).

4. Beemyn, Genny, and Susan Rankin. The Lives of Transgender People. New York: Columbia University Press, 2011.

5. Carmel, Tamar C., and Laura Erickson-Schroth. "Mental health and the transgender population." Psychiatric Annals 46 (2016): 346-49. [CrossRef]

6. Su, Dejun, Jay A. Irwin, Christopher Fisher, Athena Ramos, Megan Kelley, Diana Ariss Rogel Mendoza, and Jason D. Coleman. "Mental health disparities within the LGBT population: A comparison between transgender and nontransgender individuals." Transgender Health 1 (2016): 12-20. [CrossRef]

7. Pflum, Samantha R., Rylan J. Testa, Kimberly F. Balsam, Peter B. Goldblum, and Bruce Bongar. "Social support, trans community connectedness, and mental health symptoms among transgender and gender nonconforming adults." Psychology of Sexual Orientation and Gender Diversity 2 (2015): 281-86. [CrossRef]

8. Olson, Kristina R., Lily Durwood, Madeleine DeMeules, and Katie A. McLaughlin. "Mental health of transgender children who are supported in their identities." Pediatrics, 2016. [CrossRef] [PubMed]

9. Simons, Lisa, Sheree M. Schrager, Leslie F. Clark, Marvin Belzer, and Johanna Olson. "Parental support and mental health among transgender adolescents." Journal of Adolescent Health 53 (2013): 791-93. [CrossRef] [PubMed]

10. Bockting, Walter O., Michael H. Miner, Rebecca E. Swinburne Romine, Autumn Hamilton, and Eli Coleman. "Stigma, mental health, and resilience in an online sample of the US transgender population." American Journal of Public Health 103 (2013): 943-51. [CrossRef] [PubMed]

11. James, Sandy E., Jody L. Herman, Susan Rankin, Mara Keisling, Lisa Mottet, and Ma'ayan Anafi. The Report of the 2015 U.S. Transgender Survey. Washington: National Center for Transgender Equality, 2016.

12. Arnett, Jeffrey J. Emerging Adulthood: The Winding Road from the Late Teens through the Twenties. New York: Oxford University Press, 2004.

13. Connolly, Maureen D., Marcus J. Zervos, Charles J. Barone, Christine C. Johnson, and Christine L. M. Joseph. "The Mental health of transgender youth: Advances in understanding." Journal of Adolescent Health 59 (2016): 489-95. [CrossRef] [PubMed]

14. Reisner, Sari L., Ralph Vetters, M. Leclerc, Shayne Zaslow, Sarah Wolfrum, Daniel Shumer, and Matthew J. Mimiaga. "Mental health of transgender youth in care at an adolescent urban community health center: A matched retrospective cohort study." Journal of Adolescent Health 56 (2015): 274-79. [CrossRef] [PubMed]

15. National Center for Education Statistics. "Fast Facts: Back to school statistics. " Available online: http://nces.ed. gov/fastfacts/display.asp?id=372 (accessed on 27 December 2016).

16. Kessler, Ronald C., Patricia Berglund, Olga Demler, Robert Jin, Kathleen R. Merikangas, and Ellen E. Walters. "Lifetime prevalence and age-of-onset distributions of DSM-IV disorders in the National Comorbidity Survey Replication." Archives of General Psychiatry 62 (2005): 593-602. [CrossRef] [PubMed]

17. American College Health Association. "American College Health Association-National College Health Assessment, Spring 2009-Spring 2014 [computer file].” Hanover, MD: American College Health Association, 2009, [producer and distributor]; 2015-06-15.

18. Herman, Steve, Olga G. Archambeau, Aimee N. Deliramich, Bryan S. K. Kim, Pearl H. Chiu, and B. Christopher Frueh. "Depressive symptoms and mental health treatment in an ethnoracially diverse college student sample." Journal of American College Health 59 (2011): 715-20. [CrossRef] [PubMed]

19. Mokrue, Kathariya, and Mary C. Acri. "Subjective health and health behaviors as predictors of symptoms of depression and anxiety among ethnic minority college students." Social Work in Mental Health 13 (2015): 186-200. [CrossRef] 
20. Rosenthal, Beth Spenciner, and Arleen Cedeno Schreiner. "Prevalence of psychological symptoms among undergraduate students in an ethnically diverse urban public college." Journal of American College Health 49 (2000): 12-18. [CrossRef] [PubMed]

21. Rosenthal, Beth, and W. Cody Wilson. "Mental health services: Use and disparity among diverse college students." Journal of American College Health 57 (2008): 61-68. [CrossRef] [PubMed]

22. Eisenberg, Daniel, Sarah E. Gollust, Ezra Golberstein, and Jennifer L. Hefner. "Prevalence and correlates of depression, anxiety, and suicidality among university students." American Journal of Orthopsychiatry 77 (2007): 534-42. [CrossRef] [PubMed]

23. Oswalt, Sara B., and Tammy J. Wyatt. "Sexual orientation and differences in mental health, stress, and academic performance in a national sample of US college students." Journal of Homosexuality 58 (2011): 1255-80. [CrossRef] [PubMed]

24. Przedworski, Julia M., Nicole A. VanKim, Marla E. Eisenberg, Donna D. McAlpine, Katherine A. Lust, and Melissa N. Laska. "Self-reported mental disorders and distress by sexual orientation: Results of the Minnesota College Student Health Survey." American Journal of Preventive Medicine 49 (2015): 29-40. [CrossRef] [PubMed]

25. Rosenfield, Sara, and Dawne Mouzon. "Gender and mental health." In Handbook of the Sociology of Mental Health. New York: Springer, 2013, pp. 277-96.

26. Gleason, Hillary A., Nicholas A. Livingston, Marianne M. Peters, Kathryn M. Oost, Evan Reely, and Bryan N. Cochran. "Effects of state nondiscrimination laws on transgender and gender-nonconforming individuals" perceived community stigma and mental health." Journal of Gay E Lesbian Mental Health 20 (2016): 350-62. [CrossRef]

27. American College Health Association. “Generalizability, Reliability, and Validity Analysis." Available online: http:/ / www.acha-ncha.org/grvanalysis.html (accessed on 27 December 2016).

28. Donatone, Brooke, and Katherine Rachlin. "An intake template for transgender, transsexual, genderqueer, gender nonconforming, and gender variant college students seeking mental health services." Journal of College Student Psychotherapy 27 (2013): 200-11. [CrossRef]

29. American College Health Association. "ACHA Guidelines for trans-inclusive college health programs." Available online: http://www.acha.org/documents/Resources/Guidelines/Trans-Inclusive_College_ Health_Programs.pdf (accessed on 27 December 2016).

(C) 2017 by the authors. Licensee MDPI, Basel, Switzerland. This article is an open access article distributed under the terms and conditions of the Creative Commons Attribution (CC BY) license (http:/ / creativecommons.org/licenses/by/4.0/). 